\title{
"EL LUGAR DE LA ACCIÓN": GEOPOÉTICA Y POLÍTICA EN LO PRECARIO (2016) DE CECILIA VICUÑA
}

\author{
"The Place of Action": \\ Geopoetics and Politics in Cecilia Vicuña's The Precarious (2016)
}

\section{RESUMEN}

Cecilia Vicuña (Santiago de Chile, 1948) es una poeta, artista visual y cineasta chilena que, luego de pasar una temporada en Londres, vivió cinco años en Bogotá hasta radicarse definitivamente en Nueva York, en 1980. Aparecidos en distintos países, a lo largo de las décadas sus libros, films e instalaciones han buscado revalorizar las raíces culturales andinas a través de diferentes temáticas, materiales $\mathrm{y}$ formatos. En este trabajo ofreceremos una lectura de Lo precario, una peculiar “Antología mínima 1966-2016" en la que Vicuña repasa su carrera a partir de la selección de poemas, imágenes y reflexiones que indagan justamente acerca de "lo precario" en tanto categoría artística y conceptual. En la poética latinoamericana y transnacional de esta autora rastrearemos algunas propuestas que, partiendo de la reunión estética de desechos industriales y elementos de la naturaleza, vehiculizan una aguda crítica al presente global capitalista. Surgirá entonces un paralelo inevitable con el enfoque geocrítico, que también apunta a desestabilizar, problematizar y dar nuevo dinamismo a la percepción de los espacios humanos y los modos de habitarlos. Finalmente, evaluaremos el potencial político de esta poética a la luz de la discusión sostenida por Nicolas Bourriaud y Jacques Rancière en torno a la politicidad del arte contemporáneo.

Palabras claves: Cecilia Vicuña, Poesía Latinoamericana, Precario, Espacio, Geocrítica

\section{UNIVERSUM}

MARÍA LUCÍA PUPPO

Centro de Estudios de Literatura

Comparada "M. T. Maiorana",

Facultad de Filosofía y Letras,

Universidad Católica Argentina. CONICET, Argentina.

Correo electrónico:

mlpuppo@uca.edu.ar

ORCID: 0000-0002-4413-8306

ResearchGate: Maria Puppo4

Scholar.google:

https://scholar.google.com.ar/ citations?user=vjEXzfgAAAAJ\&hl=en Academia.edu:https://uca-ar.academia. edu/MARÍAPUPPO 


\begin{abstract}
Cecilia Vicuña (Santiago de Chile, 1948) is a Chilean poet, visual artist and filmmaker who, after spending a season in London, lived for five years in Bogotá until she finally established herself in New York, in 1980. Originated in different countries, over the decades her books, films and installations have sought to revalue Andean cultural roots through different themes, materials and formats. In this paper we will offer a reading of Lo precario, a peculiar "Minimum Anthology 1966-2016" in which Vicuña reviews her career through a selection of poems, images and reflections that inquire precisely about "the precarious" as an artistic and conceptual category. In the Latin American and transnational poetics of this author we will trace some proposals that, based on the aesthetic meeting of industrial wastes and elements of nature, convey a sharp criticism of today's global capitalism. An inevitable parallel will then arise with the geocritical approach, which also aims to destabilize, problematize and give new dynamism to the perception of human spaces and the ways of inhabiting them. Finally, we will evaluate the political potential of this poetic in the light of the discussion held by Nicolas Bourriaud and Jacques Rancière regarding the politicity of contemporary art.
\end{abstract}

Keywords: Cecilia Vicuña, Latin American Poetry, Precarious, Space, Geocriticism

\title{
UNA AUTORA Y UNA ANTOLOGÍA EN SUS CONTEXTOS
}

Cecilia Vicuña (Santiago de Chile, 1948) es poeta, artista visual, cineasta y performer. Los datos de su biografía la confirman como una poeta transnacional: nacida en la capital chilena, en los setenta pasó una temporada en Londres, luego vivió cinco años en Bogotá y, en 1980, se radicó en Nueva York. Aparecidos en distintos países, entre ellos la Argentina, a lo largo de las décadas sus libros, films e instalaciones han buceado en las raíces culturales andinas a través de diferentes temáticas, materiales, registros y formatos.

El inicio de la trayectoria de Vicuña está ligado a sus intervenciones públicas con el colectivo "Tribu No", en el Santiago de comienzos de los setenta, y la muestra Otoño (1971), para la cual la poeta llenó una sala del Museo de Bellas Artes con hojas secas (Nómez 2006). Si la libertad expresiva y el juego neovanguardista se unieron al compromiso político y la poesía erótica en los poemarios Saboramí (Londres, 1973) y Luxumei o el traspié de la doctrina (México, 1983), de las exploraciones con la poesía visual nació PALABRARmas (Samara, Colombia, 1986). En la miríada de plaquettes, catálogos y reediciones de su obra, se destaca La Wik'uña (Santiago, 1990), 
el primer poemario de la autora publicado en Chile. Allí evoca símbolos, palabras, rituales y creencias de las culturas incas, quechuas y guaraníes en busca de una "semiótica visual-táctil" de la poesía, análoga a la que el artista César Paternosto, entonces su esposo, advertía en la arquitectura incaica. Otros títulos de poesía son El Templo (Bristol, 2001), Instan (Berkeley, 2002), i tu (Buenos Aires, 2004) y El Zen Surado (Santiago, 2013), que recoge inéditos de los sesenta y los setenta. La memoria del terror en los años de dictadura vuelve en estos textos relanzados en el presente, que no han pedido su fuerza revolucionaria original.

Siempre en una actitud de búsqueda y apertura a nuevas formas de expresión, Cecilia Vicuña ha realizado importantes contribuciones al arte conceptual, la poesía fonética y el cine poético-experimental. Se ha analizado su obra como representante de la neovanguardia, anclada en una postura contracanónica (Sepúlveda 2000, 2015) que configura una peculiar "ginotradición" (Keefe Ugalde 2000) surcada por múltiples "nomadismos" (Prieto 2016). Las antologías, así como las ediciones en inglés o bilingües de los poemas, suelen incluir imágenes tomadas de intervenciones al aire libre o de muestras en museos y galerías, de modo que la interdisciplinariedad y la intersemiosis atraviesan toda la producción verbal y visual de esta autora.

El diálogo entre palabra e imagen vuelve a cobrar protagonismo en Lo precario, una peculiar "Antología mínima 1966-2016" en la que Vicuña repasa su carrera a partir de la selección de poemas, imágenes y reflexiones surgidas a lo largo de cinco décadas. Publicada en Madrid en 2016, bajo el sello Amargord Ediciones, se trata a nuestro juicio de una obra per se, cuya unidad semántica la vuelve diferente de otras antologías de Vicuña, tales como Soy Yos. Antología, 1966-2006 (Selección de la autora con Naím Nómez, Santiago, 2010), V: Antología de poesía (Edición de Renato Gómez, Lima, 2009) y Cecilia Vicuña: New and Selected Poems (Berkeley, 2017).

La idea de "lo precario" signa el pensamiento poético de Vicuña desde los años sesenta (Castro Jorquera, 2017: s/p). ${ }^{1}$ Originalmente, la autora llamó

1 Precario/Precarious se llamó una edición bilingüe de 1983 y el mismo título llevó un 
"precarios" o "basuritas" a sus pequeñas esculturas hechas con elementos de la naturaleza — caracoles, semillas, piedras - y materiales de desecho — vidrio, plástico, hilo- Como explican sus galeristas:

\begin{abstract}
Each precario ... serves as a "spatial poem" and an allegorical nod to the sociocultural and natural processes that produced, discarded, and degraded these materials.

Since beginning the body of work in the late 1960s, Vicuña has developed her practice of making precarios into a broader conversation about political struggle, the displacement and erasure of indigenous people in a time of increasing globalism, and the alarming, ever more apparent effects of climate change on the natural world. These themes now thread throughout her work in other mediums as well as her sculpture. (Lehman Maupin 2019)
\end{abstract}

Livianos y portables, los precarios han logrado existir y reproducirse en muchos medios e idiomas a la vez. Creados en y para el momento, recuperan el aura de un paisaje en fuga, amenazado, apelando a la sabiduría ancestral de los chamanes indígenas (Artishock, 2017). En primer lugar, analizaremos cómo opera la categoría de lo precario en tanto opción estética y clave de legibilidad en la peculiar antología de textos de Vicuña editada por Amargord. Entonces surgirá un paralelo inevitable entre la propuesta de la autora chilena y el enfoque geocrítico, que también apunta a desestabilizar, problematizar y dar nuevo dinamismo a la percepción de los espacios humanos y los modos de habitarlo. Para concluir, evaluaremos el potencial político de esta obra de Vicuña a la luz del debate sostenido por Nicolas Bourriaud y Jacques Rancière en torno a la politicidad del arte contemporáneo.

\title{
LO PRECARIO: MODELIZACIÓN ESTÉTICA Y CLAVE DE LEGIBILIDAD
}

El texto que nos ocupa posee una estructura en espejo articulada en

importante volumen editado por Catherine de Zegher en 1997. Asimismo, "Precarios" se llama una sección de la muestra About to Happen, retrospectiva de la obra de Vicuña que ha sido alojada en varios museos norteamericanos: Contemporary Arts Center (Nueva Orleans, 2017), University of California Art Museum (Berkeley, 2018), Institute of Contemporary Art (Philadelphia, 2019) y Henry Art Gallery (Seattle, 2019). 
dos grandes secciones: "Lo PRECARIO 1966-1981" y "Lo PRECARIO 19852016". Cada una de estas secciones está compuesta, a su vez, por seis poemas presentados como "Seis metáforas espaciales" (15 y 79). A lo largo de sus páginas, los textos poéticos son intercalados por fotos de obras e instalaciones de Vicuña generalmente hechas al aire libre, en entornos naturales. Se trata de fotografías en blanco y negro que muestran composiciones muy logradas. Tras las secciones gemelas, sigue el apartado "Textos PRECARIOs", donde la poeta reúne citas propias y de otros autores/as, junto con anécdotas biográficas y reflexiones surgidas en distintos momentos de su trayectoria poética y vital. Al final se incluyen dos páginas de "Notas al texto" y una de "Créditos fotográficos".

Cada poema indica un lugar y una fecha después del título. En ellos la precariedad se revela ante todo como una modelización estética, es decir, como un "sistema" ordenador en el que se inscriben los diversos textos. ${ }^{2}$ Los poemas y las fotografías en diálogo con ellos operan con el encuadre, la selección y la síntesis de elementos, estrategias que muchas veces coinciden en la metonimia. En "Sendero Chibcha. Colombia, 1981" leemos, por ejemplo:

La poesía habita
algunos lugares
donde los riscos
no necesitan
sino ser señalados
para vivir:

dos o tres líneas una marca y el silencio empieza a hablar. (58)

Esta primera parte vincula los antiguos caminos de montaña indígenas con el trabajo de la poesía: minimalismo de la expresión que captarán las

2 Tomamos el término en el sentido que le dio Yuri Lotman, quien definió al arte y la literatura como "sistemas modelizadores secundarios" que actúan sobre el sistema primario de la lengua (1982: 51-52) 
instalaciones de Vicuña trazando líneas suaves en el paisaje andino, hilos que se sostienen con plumas enclavadas como estacas (63). En una segunda secuencia de versos, prosigue la descripción espacial:

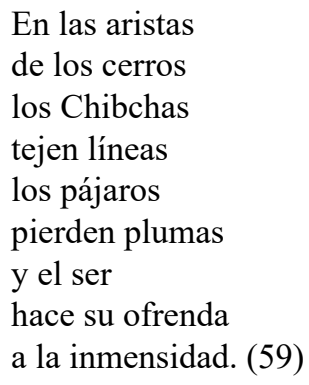

Advertimos que cerros y pájaros aparecen como dos emblemas que resumen el dinamismo espacial de la mirada-escritura, que va de lo macro a lo microscópico, y viceversa. Como sucede en las obras exhibidas en museos de Vicuña, el cosmos y la miniatura se dan cita unidos por el instante azaroso del hallazgo. Esa dualidad también está presente en "Tunquén. Chile 1981", donde se lee:

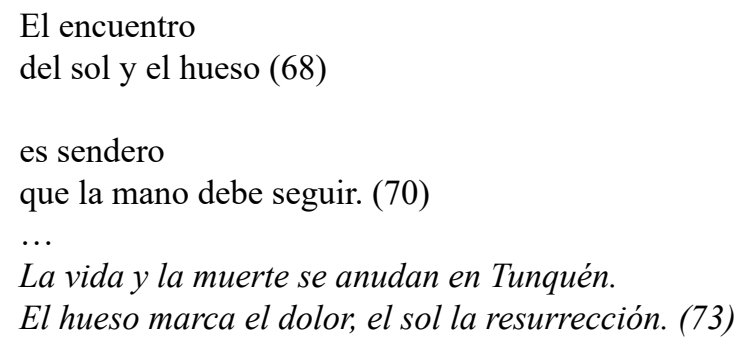

A este último dístico le sigue una secuencia de imágenes acompañadas pos dos sintagmas: "Senderos de huesos" (74), "El cuerpo desaparecido" (75). La primera fotografía muestra la falda recogida de una mujer arrodillada, como si estuviera a punto de dar a luz, donde se acumulan ramitas que llegan hasta la arena. 


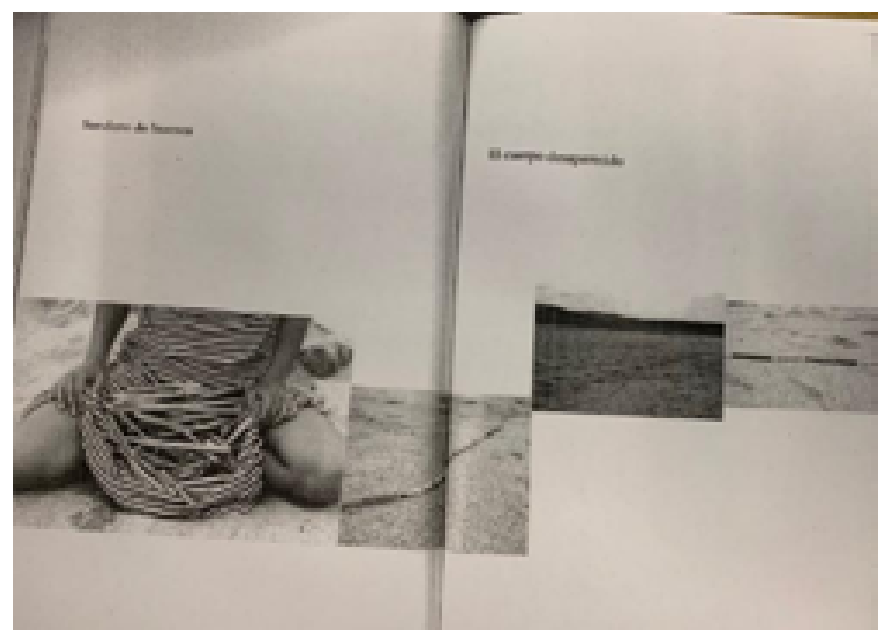

1. Lo precario, pp. $74-75$.

En las siguientes fotos se ve un sendero de palitos trazado sobre una playa o un desierto. Inmediatamente después, un breve relato explica el origen de estas asociaciones:

El 11 de septiembre de 1973 durante el golpe militar en Chile, yo estaba en Londres estudiando arte. En mis primeros regresos al país, a fines de los 70's, vi que mis amigas buscaban huesos, cualquier hueso, para representar los cuerpos de sus amados asesinados y desaparecidos después del golpe. En mi propia familia, también hubo desaparecidos.

Realicé la obra Tunquén pensando en ellas, en su búsqueda interminable del cuerpo no habido. (76)

Los elementos de la naturaleza se unen para evocar el horror de la historia chilena y sudamericana: palitos que se vuelven huesos. Luego la poeta reflexiona sobre su acción imprevista, no planeada, de colocar los palitos sobre su vestido. ${ }^{3}$ En sus propias palabras, adviene de ese modo una "curación

3 Vicuña reproduce, a continuación, la cita de un testimonio oral que dio al Museo de Arte Contemporáneo de Chile, donde se encuentra la obra: “... empecé a recoger estos palitos, entonces él [mi hermano Ricardo] capta el momento en que me los pongo en el útero. Entonces los palitos son como criaturas que van saliendo del útero y van quedando desparramados como niños huérfanos y asociados en una línea ancestral, una línea de memoria que está siendo atacada por la desaparición de nuestros seres" (76). 
del dolor" que visualiza los huesos perdidos para devolverles una presencia y acunarlos "como niños huérfanos" (76). El gesto reparador se prolonga en la instalación fotografiada, donde se distingue el trazado de una línea delgada hecha con lanas y otros materiales - sobre la playa de Tunquén. Es notable que las dos escenas representadas recurren a la alegoría en un doble dinamismo de concentración y expansión, pues el simulacro de parto-abrazo acerca y reúne a los desaparecidos, en tanto que la incorporación de los palitos en la línea apunta a restituirles su lugar en la cadena de las generaciones, proyectando su obrar en el curso de la historia.

Además de una opción estética, lo precario resulta una clave de legibilidad, un lente para captar el momento presente desde el lugar frágil e incómodo en que se sitúa la hablante poética. Así se advierte en "Cruz del sur. Colchagua 1994": en primer lugar, una foto muestra una obra lumínica de Cecilia Vicuña (pág. 87); la página siguiente se ve atravesada por un poema-acróstico en forma de cruz, rodeado de citas del antropólogo Reichel Dolmatoff referidas a rituales de los Kogi.

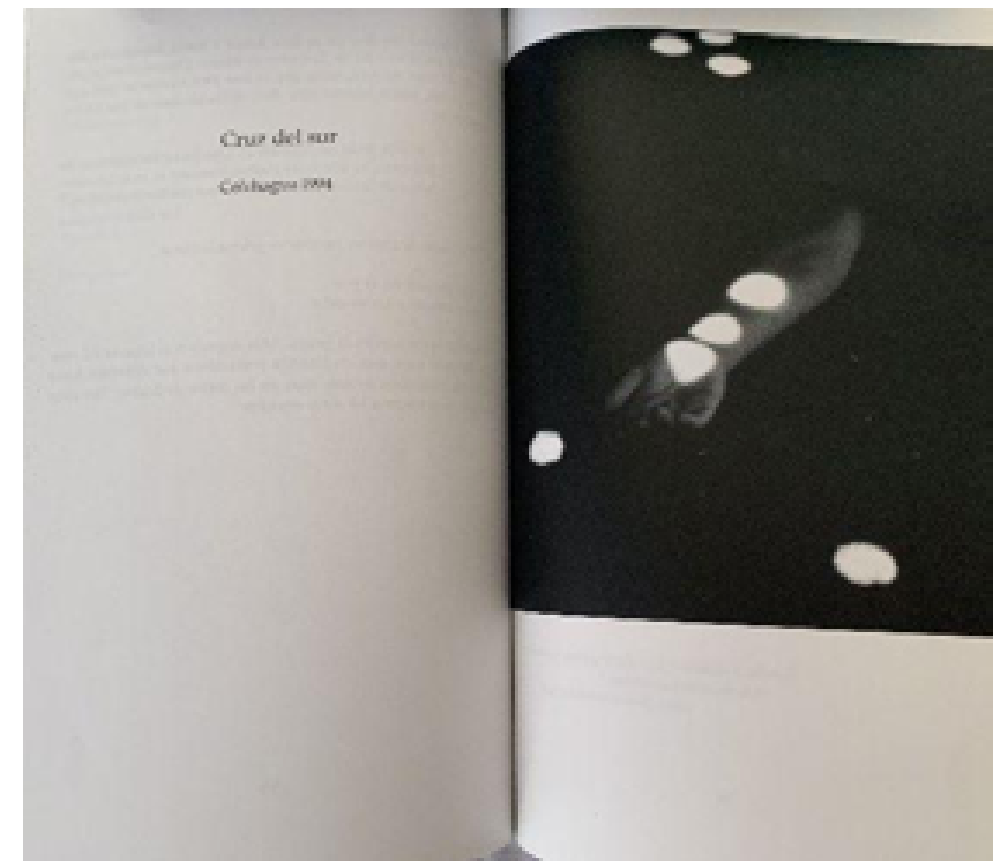

2. Lo precario, páginas 86-87. 


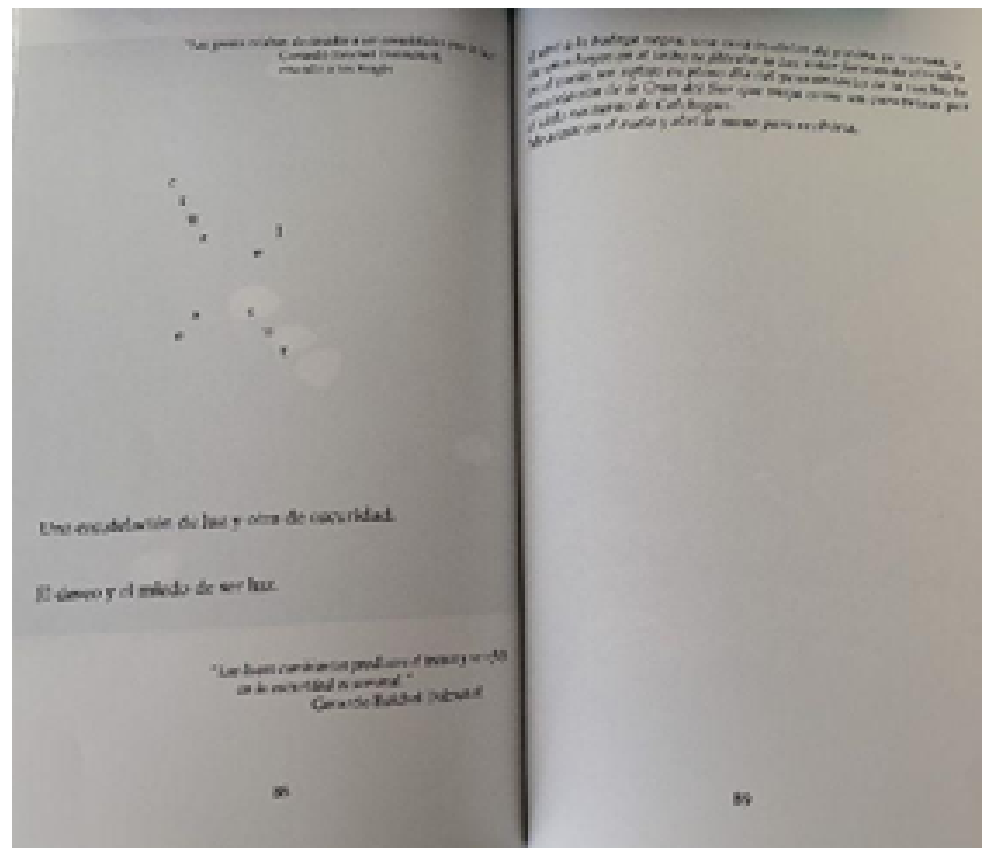

3. Lo precario, páginas $88-89$.

Finalmente, en cursiva llega el relato biográfico que explica las circunstancias que dieron origen a la obra y el poema:

Entré a la bodega negra, una casa incásica de piedra en ruinas, y de unos hoyos en el techo se filtraba la luz solar formando círculos en el suelo, un reflejo en pleno día del pensamiento de la noche, la constelación de la Cruz del Sur que viaja como un parabrisas por el cielo nocturno de Colchagua.

Me acosté en el suelo y abrí la mano para recibirla. (89)

Según su propia explicación lo indica, en los juegos de la luz diurna la poeta lee la constelación de la noche, y en esa imagen casual, intangible, evanescente, propone un símbolo de la noche oscura latinoamericana. El poema nos devuelve entonces una especie de mapa invertido ${ }^{4}$, un plano caprichoso de estrellas sobre una mano abierta al ras del suelo.

Advertimos que lo precario como clave de lectura del mundo implica

4 Esta Cruz del Sur que aparece de noche bien podría asociarse al famoso mapa invertido de Torres García, que posiciona a América del Sur como norte. 
la renuncia a un lugar de enunciación pretendidamente único e integrador. No hay "una voz" sino múltiples voces que modulan el texto; y lo mismo puede decirse de los tonos, los temas y los espacios abordados. En este sentido, el sistema de lo precario es asimilable a la perspectiva geocrítica tal como la plantea, en el seno del Comparatismo, el teórico Bertrand Westphal. Esta disciplina invita a pensar los espacios humanos más allá de su "superficie de evidencia" (Westphal, 2015: 36), apelando a la constante desterritorialización y multiplicación de las percepciones espaciales y subrayando en ellas el cruce de puntos de vista (multifocalización), capas (estratografía), temporalidades (asincronía) y registros del sensorio (polisensorialidad). Desde un enfoque interdisciplinario, la Geocrítica apunta a cuestionar las representaciones del espacio, especialmente aquellas que se inclinan a confirmar estereotipos de región o nación. Según Westphal, la literatura y el arte ofrecen miradas más complejas, superadoras de la "impostura cartográfica" que reposa sobre la exactitud legitimante del mapa, que suele funcionar como "instrumento de una domesticación del territorio del Otro" (Westphal 2011: 221). En el caso de la poesía de Vicuña, el mapa - ya sea que esté trazado sobre el suelo o sobre el cuerpo femenino - resulta dudoso y problemático. Es en este sentido que la geopoética que delinean los versos y las fotografías de la autora chilena ofrecen una auténtica problematización del espacio y sus representaciones, huyendo siempre de las peligrosas (y solo aparentes) "geografías estables" (Westphal 2019: 16).

Los textos verbales e icónicos que integran el libro de Vicuña examinado proponen vínculos armoniosos, reparadores entre los espacios y sus habitantes (personas, animales, plantas) pero también, las más de las veces, denuncian la ruptura de esos lazos. Resulta muy significativo al respecto el poema "Vaso de leche. Bogotá 1979", antecedido por las fotografías de una intervención artística muy sencilla, que consistió en derramar un vaso de leche sobre la tierra:

5 Las traducciones son nuestras. 


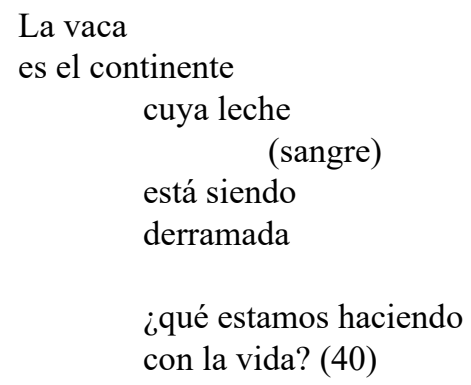

Como explica la autora, el poema y la intervención surgieron en el marco de CADA, Colectivo de Acciones de Arte, a raíz de la alarmante noticia de que "1920 niños mueren anualmente en Bogotá por consumir leche contaminada en el país" (42). Testimonio, compromiso, empatía con el dolor humano, trabajo con la memoria y denuncia de la injustica son "gestos líricos" de la poesía y el arte de Cecilia Vicuña que invitan a reflexionar acerca de los vínculos entre arte y política ${ }^{6}$.

\section{EL LUGAR DE LA ACCIÓN}

En un artículo que analiza QUIpoem (1997), otro volumen de Vicuña que combina poemas y obras visuales, Juliet Lynd señala que la estética precaria habilita un modo de representación que "niega significaciones fijas y privilegia conexiones creativas, postulando lo efímero como un gesto de esperanza frente a los discursos hegemónicos del poder" (2005: 1592). ${ }^{7} \mathrm{La}$ antología en torno a Lo precario confirma que, desde sus inicios, la obra de Vicuña estuvo atravesada por temas urgentes de la agenda política. Con alegría declaraba la autora en una reciente entrevista que su obra ahora adquiere relevancia porque "el eje de la sociedad cambió al sur" y vemos "un espíritu de rebelión, de oposición, especialmente de los jóvenes, hacia el capitalismo

6 Apelamos deliberadamente a la fórmula de "gestes lyriques" desarrollada por Dominique Rabaté (2013), que pone el foco en la performatividad de la poesía moderna.

7 La traducción es nuestra. 
salvaje" (Ramón Ríos, 2018: s/p). La crítica del consumo y la reivindicación de las culturas amerindias que propone la obra de Vicuña se inscriben en el contexto del indigenismo actual. Como lo demuestra J. F. Alvergue (2014) a partir del estudio de la apropiación que hace la autora de la figura del espiral, es mediante operaciones estéticas que su poesía y su arte construyen formas alternativas de saber ligadas a tradiciones precolombinas.

Es posible considerar el mensaje político de la obra analizada a la luz del debate en torno a los vínculos entre arte y política protagonizado por Nicolas Bourriaud y Jacques Rancière hace unos años. En un conocido artículo incluido en El espectador emancipado (2010), Rancière se manifestó contra la ilusión de un arte "cuyos dispositivos se presentan directamente como proposiciones de relaciones sociales" (71). Criticaba de ese modo la hipótesis acerca de la "estética relacional" propugnada por Nicolas Bourriaud, curador y crítico de arte que llamó la atención sobre las obras producidas en colaboración, al estilo de meetings y happenings, donde se produce la interacción entre autor(es) y espectadores y los espacios museísticos devienen en lugares de convivialidad. La crítica de Rancière apuntaba contra el optimismo de Bourriaud de ver allí una inversión o puesta en suspenso de los vínculos sociales jerárquicos, que plantearía una especie de "microutopía" e invitaría al cambio social. El filósofo francés invitaba, por el contrario, a desterrar la falsa idea de que existe "una transmisión calculable entre conmoción artística sensible, toma de conciencia intelectual y movilización política" (69). De ese modo, Rancière tomaba un punto de vista definitivamente lejano de las posturas de un Sartre o un Brecht, apóstoles del compromiso artístico de otro tiempo. Es muy conocida la conclusión a la que arribaba el pensador contemporáneo: "Un arte crítico es un arte que sabe que su efecto político pasa por la distancia estética" (84).

Entendemos que la poética verbovisual precaria de Cecilia Vicuña pertenece a este último tipo de arte descrito por Rancière. Aunque se ocupen de problemas que claman a gritos desde el contexto referencial -como la tortura y el exterminio, el hambre infantil, la desigualdad económica, la violencia de género, la injusticia y la polución-, las obras de la autora chilena siempre involucran dispositivos y estrategias estéticas que mediatizan la experiencia 
de los/as lectores/as y espectadores/as. Hemos comprobado que, aun cuando los relatos que acompañan los versos y las fotografías de Lo precario apunten a subrayar el carácter testimonial -muchas veces azaroso e imprevisto- del origen de las obras, en todos los casos se evocan imágenes y materiales que funcionan como metonimias o alegorías que invitan a la decodificación simbólica por parte de los/as receptores/as. La reflexión y la toma de conciencia surgen en un paso ulterior, traspasado el primer umbral sensorial y artístico de las obras.

Hay aún otra fase de la polémica Rancière-Bourriaud que podemos relacionar estrechamente con el universo de Vicuña. En el 2009 Bourriaud respondió a las críticas del filósofo en un artículo titulado, justamente, "Precarious Constructions: Answer to Jacques Rancière on Arts and Politics". Allí el curador sostenía que Rancière no había comprendido el sentido de su teoría sobre el arte relacional. Para explicarse mejor, Bourriaud invocaba la noción de precariedad asociada a la "modernidad líquida" descrita por Bauman que entroniza, como se sabe, la primacía de lo renovable, lo descartable y lo transitorio. En esa oportunidad, Bourriaud enumeró tres rasgos del arte precario que coinciden en buena medida con las características que observamos en la obra de Vicuña: el nomadismo formal, la intermitencia y la difuminación o borrosidad $^{8}$. Evidentemente, los poemas y las obras visuales de la autora chilena operan con estas estrategias compositivas, creando o recreando conexiones entre signos distantes. ¿Esto significa que, en nuestro razonamiento a partir de la obra de Vicuña, queda finalmente zanjada la distancia entre la argumentación de Rancière y la de Bourriaud? Creemos que sí, al menos en lo que respecta a la politicidad del arte de Vicuña, pues esta segunda propuesta de Bourriaud ya no identifica ingenuamente el vínculo entre percepción (sensorial) y agencia (política), sino que subraya, en cambio, el rol de mediadores estéticos que cumplen los recursos propios de las "construcciones precarias". A nuestro entender, metonimias, alegorizaciones, montajes, inversiones, yuxtaposiciones

8 Traducimos libremente la triple fórmula de Bourriaud: a) "Permanent transcoding: formal nomadism", b) "Flickering: intermittences", y c) "Blurring: the Indiscernible". 
de elementos, miniaturas, descontextualizaciones, diálogos entre palabra e imagen son algunas de esas estrategias que operan con "singularidades concretas" (Bourriaud) e invitan al "disenso sensorial" (Rancière). En una serie de los "textos precarios" fechada en 1996, en Nueva York, la poeta escribe:

El arte es una forma de ver y oír.

El poema es la forma de la percepción.

"Uno mismo debe ser el lugar de la acción" Meister Eckhart

Con la densidad y el poder de síntesis que les son propios, la poesía contemporánea y el arte conceptual amplían el registro de la percepción ("ver y oír"), provocando de ese modo un acontecimiento, una auténtica experiencia en quienes se acercan a ellos. En el caso de Vicuña, esa experiencia tiene que ver con una reconexión con el medio ambiente y una vuelta a los orígenes del canto. Y este remite al universo ancestral de la plegaria, palabra que - como recuerda la poeta - se remonta al igual que precario al verbo latino precor, que significaba 'rogar, suplicar, desear'. Lo precario equivale en cierto modo a lo que se espera y se desea a partir de los ruegos, las preces. Es lógico entonces que lo precario suceda, en primer lugar, en el interior de las personas: lo sabía el místico renano y también el Buddha, el andino, el winnebago y el khakassy, todos ellos maestros espirituales citados por Vicuña (126).

Desde el punto de vista filosófico, la cuestión de la precariedad de la vida fue analizada por Emmanuel Lévinas en el planteamiento de una ética de la no violencia. Sobre el tema volvió posteriormente Judith Butler (2006) en una serie de ensayos escritos en los meses posteriores al atentado contra las Torres Gemelas. Allí la autora norteamericana reflexionaba sobre la vulnerabilidad y la agresión como puntos de partida de la vida política. Ahora bien, en estudios más recientes Butler ha insistido en que las nociones de vulnerabilidad y precariedad no tienen necesariamente que ver con instancias de violencia $o$ daño físico o psíquico (Navarro Ruiz 2016: 188). Por el contrario, dado que es 
una cualidad de todos los cuerpos, "la vulnerabilidad puede ser una noción de apertura", "de estar abierto a un mundo que no se conoce ni se puede predecir completamente" (Butler, 2015: 149). Esta misma conciencia acerca de la precariedad y vulnerabilidad humanas recorre la geopoética de Cecilia Vicuña, aquella que elige "trabajar en las zonas sacrificiales de conflicto donde el ataque a la vida avanza destruyendo culturas, lenguas y ecosistemas" (Vicuña, 2016: 120), aquella que también busca "oración" modulada en distintas lenguas y creencias para unirse en "la conciencia del sí colectivo" (130).

Ya hemos señalado que, en su intento por desestabilizar, problematizar y dar nuevo dinamismo a la percepción y representación de los espacios, la estética precaria coincide con el enfoque epistemológico de la Geocrítica. $\mathrm{Su}$ poder de agenciamiento político consiste en ampliar la percepción, problematizar los marcos de referencia, cuestionar los usos que hacemos de los materiales y proponer nuevos modos de relación con la naturaleza y el paisaje. Se trata, a todas luces, de una geopoética-crítica latinoamericana que bucea en lo andino como patrimonio simbólico, en tanto tradición cultural respetuosa del silencio y del entorno natural, atenta al detalle y la interacción del aire, el agua y la luz con los dones de la tierra. En su propuesta cabe justamente lo que no entra en los mapas y en las fórmulas científicas: relatos transmitidos oralmente, enunciaciones corales, símbolos, frases y rituales que posibilitan la ternura entre humanos, el intercambio pacífico con todos los seres y la apertura a lo sagrado. Es desde este lugar complejo, en el cruce de discursos, prácticas y saberes, que la poética precaria de Cecilia Vicuña resiste las violentas lógicas del utilitarismo, el consumo y la eficiencia. Sus armas son estéticas y operan en la transformación de los/as receptores/as: allí radica su fuerza política, pues ya sea que causen el gozo contemplativo o la perturbación, en todos los casos sacan a los sentidos de la rutina para sumergirlos en una dimensión poética, cósmica, al mismo tiempo actual y amerindia. 


\section{REFERENCIAS}

Alvergue, José Felipe. "Twentieth-Century Experiments in Form: A Critical

Re-reading of Cecilia Vicuña's Indigenism as Episteme". Comparative Literature 66/2 (2014): 208-226.

Artishock. "Primera individual de Cecilia Vicuña en Estados Unidos". 20/4/17.

http://artishockrevista.com/2017/04/20/primera-individual-ceciliavicuna-estados-unidos/

Bourriaud, Nicolas. "Precarious Constructions: Answer to Jacques Rancière on Arts and Politics". A Precarious Existence: Vulnerability in the Public Domain. Rotterdam: NA, 2009: 20-36.

https://onlineopen.org/download.php?id=240

Butler, Judith. Vida precaria. El poder del duelo y la violencia. Buenos Aires: Paidós, 2006.

Notes Toward a Performative Theory of Assembly. Cambridge, Londres: Harvard University Press, 2016.

Castro Jorquera, Carolina. "We are all indigenous: listening to our ancient thought". Terremoto, 9, 17/7/2017. https://terremoto.mx/article/weare-all-indigenous-listening-in-on-our-ancient-thought/

Keefe Ugalde, Sharon. "Diseños de una ginotradición (Rosario Castellanos, Pat Mora y Cecilia Vicuña)". INTI 51 (2000): 53-68.

Lehman Maupin. "Cecilia Vicuña: Lo Precario / The Precarious, Wexner Center for the Arts de Columbus, Ohio, 1 junio-11 agosto de 2019". https://www.lehmannmaupin.com/museums-and-global-exhibitions/ cecilia-vicuna-lo-precario-the-precarious

Lynd, Juliet. "Precarious Resistance: Weaving Opposition in the Poetry of Cecilia Vicuña”. PMLA 120/5 (2005): 1588-1607.

Lotman, Yuri. Estructura del texto artístico. Madrid: Istmo, 1982.

Navarro Ruiz, Clara. "Precariedad, vulnerabilidad y cuerpos en la calle". Oxímora, Revista internacional de Ética y Política 8 (2016): 185-190. 
Nómez, Naím. Antología crítica de la poesía chilena. Tomo IV, Modernidad, marginalidad y fragmentación urbana (1953-1973). Santiago: LOM, 2006.

Prado, Marcela. "Debate crítico alrededor de la Estética Relacional". Disturbis 10 (2011). https://ddd.uab.cat/pub/disturbis/disturbis_a2011n10/ disturbis a2011n10a2/Prado.html

Prieto, Julio. "Hilos transversales: nomadismo en la poesía de Cecilia Vicuña". Poéticas del presente. Ottmar Ette y Julio Prieto (eds.). MadridFrankfurt: Iberoamericana-Vervuert, 2016: 237-258.

Rabaté, Dominique. Gestes lyriques. París: José Corti, 2013.

Ramón Ríos, Mónica. "Cecilia Vicuña, poeta y artista visual: una obra que encuentra su contexto". El desconcierto, 3/6/18. https://www. eldesconcierto.cl/2018/06/03/cecilia-vicuna-poeta-y-artista-visualuna-obra-que-encuentra-su-contexto/

Rancière, Jacques. "Las paradojas del arte político". El espectador emancipado. Buenos Aires: Manantial, 2010: 53-84.

Sepúlveda, Magda. "Cecilia Vicuña: la subjetividad poética como una operación contracanónica”. Revista Chilena de Literatura 57 (2000): 111-126.

"Una neovanguardia hippie: Cecilia Vicuña". Vicuñiana: el arte y la poesía de Cecilia Vicuña, un diálogo Sur/Norte. Meredith Gardner Clark (ed.). Santiago de Chile: Editorial Cuarto Propio, 2015: 65-81.

Vicuña, Cecilia. Lo precario. Antología minima 1966-2016. Madrid: Amargord Ediciones, 2016.

Westphal, Bertrand, Le monde plausible. Espace, lieu, carte. París: Minuit, 2011.

Atlas des égarements. Études géocritiques. París: Minuit, 2019.

“Aportes para un enfoque geocrítico de los textos". Espacios, imágenes $y$ vectores. Desafios actuales de las literaturas comparadas. Mariano García, María José Punte y María Lucía Puppo (eds.). Buenos Aires: Miño y Dávila, 2015: 27-57. 
Zegher, Catherina de (ed.). The Precarious. The Art and Poetry of Cecilia Vicuña. Hanover, NH: Wesleyan UP, 1997. 